\title{
Structural Strengthening of Urchin Skeletons by Collagenous Sutural Ligaments
}

\author{
OLAF ELLERS ${ }^{1}$, AMY S. JOHNSON ${ }^{2 * *}$, AND PHILIP E. MOBERG ${ }^{3}$ \\ ${ }^{1}$ Section of Evolution and Ecology, Division of Biological Sciences, University of California, \\ One Shields Ave., Davis, California 95616; 2** Biology Department, Bowdoin College, \\ Brunswick, Maine 04011; and ${ }^{3}$ Marine Biology Research Division, Scripps Institution of \\ Oceanography, University of California, San Diego, La Jolla, California 92093-0202
}

\begin{abstract}
Sea urchin skeletons are strengthened by flexible collagenous ligaments that bind together rigid calcite plates at sutures. Whole skeletons without ligaments (removed by bleaching) broke at lower apically applied forces than did intact, fresh skeletons. In addition, in three-point bending tests on excised plate combinations, sutural ligaments strengthened sutures but not plates. The degree of sutural strengthening by ligaments depended on sutural position; in tensile tests, ambital and adapical sutures were strengthened more than adoral sutures. Adapical sutures, which grow fastest, were also the loosest, suggesting that strengthening by ligaments is associated with growth. In fed, growing urchins, sutures overall were looser than in unfed urchins. Looseness was demonstrated visually and by vibration analysis: bleached skeletons of unfed urchins rang at characteristic frequencies, indicating that sound traveled across tightly fitting sutures; skclctons of fed urchins damped vibrations, indicating loss of vibrational energy across looser sutures. Furthermore, bleached skeletons of fed urchins broke at lower apically applied forces than bleached skeletons of unfed urchins, indicating that the sutures of fed urchins had been held together relatively loosely by sutural ligaments. Thus, the apparently rigid dome-like skeleton of urchins sometimes transforms into a flexible, jointed membrane as sutures loosen and become flexible during growth.
\end{abstract}

\section{Introduction}

Animal skeletons commonly consist of rigid ossicles connected by flexible ligaments. In this design, rigid ele-

\footnotetext{
Received 30 January 1998; accepted 12 June 1998.

* To whom correspondence should be addressed. E-mail: ajohnson@ polar.bowdoin.edu
}

ments resist compression and bending, whereas flexible elements resist tension and allow flexion. Vertebrate limb joints and echinoderm skeletons are examples of this design. Echinoderm skeletons are composed of calcite ossicles and collagenous connective tissues in a ratio that differs among taxa (Moss and Meehan, 1967). In sea cucumbers, for instance, collagenous tissues predominate, whereas in most sea urchins, calcite plates predominate. In the current study, we investigate the structural role of the collagenous ligaments that bind together the calcite plates in urchin skeletons.

The perforated calcite plates are attached to each other at sutures by ligaments (Fig. 1) that wrap around calcite rods (trabeculae), thus sewing together adjacent plates (Muss and Meehan, 1967). In addition, trabeculae project from one plate into holes in the adjacent plates, thus interlocking the plates. Ligaments are present to various degrees depending on the species and on the position of a suture on an urchin (Telford, 1985a). For instance, meridional (= vertical or radial or zig zag) sutures tend to have more ligaments than do circumferential (= horizontal or hoop) sutures. Also, some regions of the skeleton have relatively many sutures and smaller plates. For instance, the ambulacral regions (where the tube foot rows are located), are composed of many small plates (one plate per tube foot). In contrast, the interambulacral regions have larger plates and fewer sutures. The skeletal structure is completed by the peristomial membrane, which is attached at the oral margin. This membrane is a tough but flexible collagenous tissue (sometimes with calcite ossicle inclusions) that bridges the gap between the Aristotle's lantern (or jaw) and the skeleton (Wilkie et al., 1993).

Urchin skeletons grow both by the accretion of calcite 


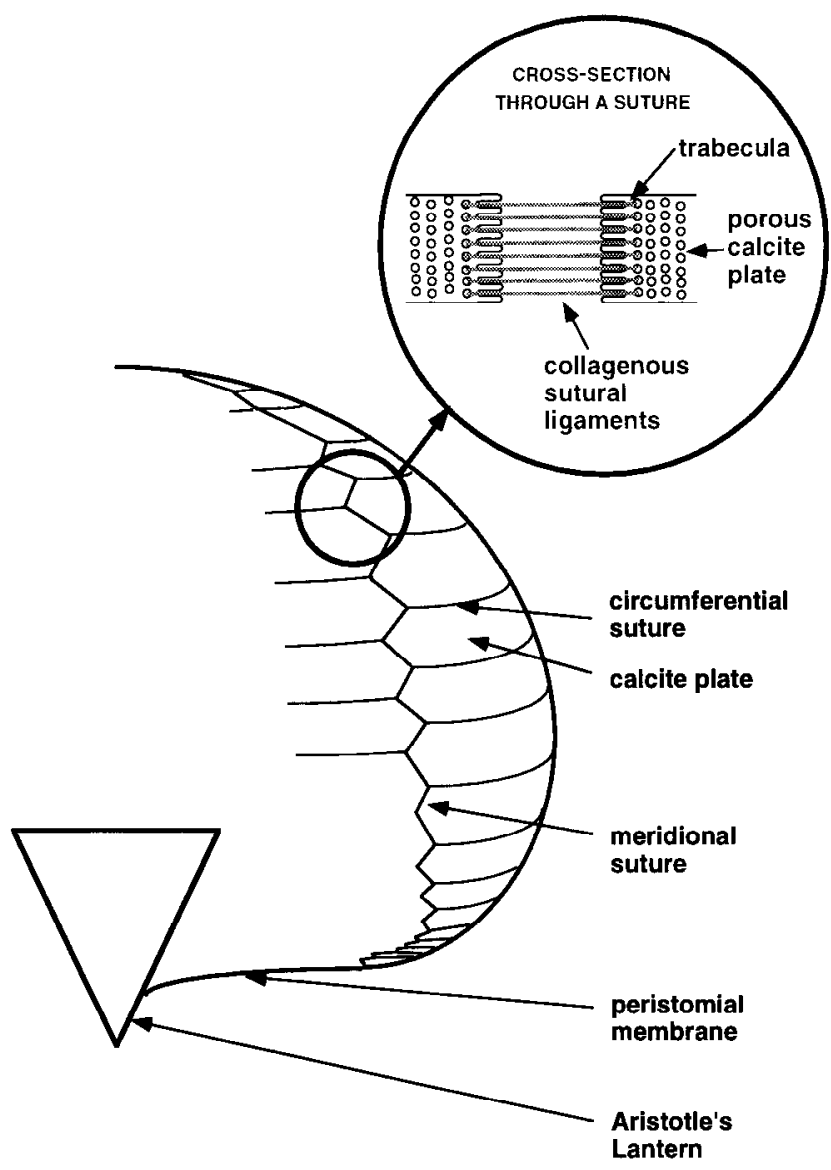

Figure 1. Schematic of interambulacral suture geometry and sutural ligament attachment. Interambulacral, meridional, and circumferential sutures arc illustrated. Ligaments bind together adjacent plates (magnified inset of cross-section of a suture).

at the edges and faces of the plates and by the addition of new plates at the apex (Deutler, 1926). Initially apical, new plates gradually migrate adorally during growth. Skeletal plates may show seasonal or yearly growth rings that reflect changes in growth rate (Gage, 1991, 1992a, b) or spurts of growth (Pearse and Pearse, 1975). Urchins may also shrink under conditions of lowered food availability or overcrowding, as observed, for example, in Diadema antillarum (Levitan, 1988), and in Strongylocentrotus purpuratus (Ebcrt, 1967). In Heliocidaris erythrogramma, shrinkage is associated with diminution of sutural gaps (Constable, 1993).

That sutural ligaments might strengthen the skeleton was suggested in a taphonomic study in which decomposed urchin skeletons disarticulated at sutures and broke at lower forces than did undecomposed urchin skeletons (Kidwell and Baumiller, 1990). On the basis of histological and morphological evidence, sutural ligaments were interpreted as "stress-breakers" that evenly distribute stresses and thus contribute to the structural integrity of echinoid skeletons (Moss and Meehan, 1967). In other theoretical and experimental studies of the structural mechanics of echinoid skeletons (Telford, 1985b; Dafni, 1986, 1988; Baron, 1991a, b; Fllers, 1993; Philippi and Nachtigall, 1996), the possible structural role of the sutural ligaments has not been a focus. Nor has a possible structural role for the peristomial membrane been tested. Although this membrane is not flexurally stiff relative to the calcite plates, it might provide tensile reinforcement to the skeleton, as do steel tensile reinforcement rods across the span of concrete bridge arches.

To determine the relative contributions of skeletal components (sutural ligaments, peristomial membrane, and calcite plates) to the structural strength of urchin skeletons, we measured breaking forces of entire skeletons and excised portions of skeletons of $S$. purpuratus, with soft tissues either present or removed. To evaluate possible sutural changes during growth, we used breaking and vibration tests as well as visual inspection to compare the looseness of sutures in fed, growing specimens of $S$. purpuratus with that in unfed, nongrowing specimens.

\section{Materials and Methods}

\section{Testing device}

A motor-driven device and force beam were used to apply a load at a rate of $200 \mu \mathrm{m} \mathrm{s}^{-1}$ to various specimens until they broke. The force signal was amplified, digitized (12-bit, $100 \mathrm{~Hz})$, and stored in a computer. Error in the force measurements was $< \pm 0.1 \mathrm{~N}$. Prior to breaking tests, the height and diameter of all urchins were measured to $\pm 0.1 \mathrm{~mm}$ with calipers.

\section{Crushing of whole skeletons}

Strongylocentrotus purpuratus was collected subtidally at Bodega Bay, California. Urchins were assigned at random to three groups, each prepared for crushing tests in a different way: (i) live unaltered, i.e., with peristomial membrane and sutural ligaments intact; (ii) peristomial membrane and Aristotle's lantern removed, i.e., with sutural ligaments intact; and (iii) bleached and air-dried, i.e., with no soft tissues intact. The bleaching chemical was $5.25 \%$ sodium hypochlorite. Sufficient bleach was added until all soft tissues had been dissolved and washed away. The prepared skeletons were crushed along the oral-aboral axis.

\section{Three-point breakage of plates and meridional sutures}

S. purpuratus was collected intertidally at Pillar Point, California. Urchins were kept in a $12^{\circ} \mathrm{C}$ recirculating seawater system for less than a week prior to mechanical tests.

Pieces of skeleton consisting of various combinations of plates and sutures were prepared for mechanical testing as follows. From each urchin, two homonomous, ambital, interambulacral plates were cut out using a Dremel tool. 
As a control, one plate was bleached overnight prior to testing, and the other plate was tested to breakage while fresh (held for less than $1 \mathrm{~h}$ in $12^{\circ} \mathrm{C}$ seawater prior to testing). In addition, two sets of homonomous, three-plate combinations, joined to each other at a meridional, ambital, interambulacral suture were cut out. Again, one set was bleached overnight prior to testing and the other was tested to breakage while fresh.

For mechanical testing, each test piece was placed on the base platform, which was coated lightly with mineral oil to reduce friction. Each test piece formed a shallow arch and, as the piece was driven into the platen to which the load cell was attached, force was applied by a cylindrical rod (diameter $1 \mathrm{~mm}$ ) to the apex of the arch, till breakage occurred. Thickness and width at the broken section were measured to $\pm 0.1 \mathrm{~mm}$ using calipers. Breaking forces were compared to determine if there was a significant reduction in breaking force after bleaching. Because of the complex geometry of the beams, we compared breaking forces of homonomous specimens paired for size rather than comparing estimated stresses.

\section{Tensile tests of circumferential sutures}

S. purpuratus was obtained from a subtidal population near Bodega Bay. One group was bleached and air-dried before testing; the other group was tested fresh. Groups of interambulacral plates were excised from three regions on the skeleton: adapical, ambital, and adoral. The ambital region was defined to be four plates wide, centered at the widest diameter of the urchin. The adapical region was defined as starting three plates above the uppermost ambital plate. The adoral region was defined as starting two plates below the lowest ambital plate.

For each tensile test, the strength of a circumferential suture was measured. Each test piece was excised and consisted of a column of four plates. The test piece was attached to the testing device using strands of copper wire that were looped through holes $(1.2 \mathrm{~mm}$ in diameter) drilled in the test piece. The holes in the test piece were located in the middle of the plates immediately adjacent to the suture being tested. Thickness and length of the cross-sectional area being broken were measured to $\pm 0.1 \mathrm{~mm}$ using calipers. These measurements were used to calculate a nominal stress; nominal because the porous nature of the plates and sutures makes it impractical to measure an actual cross-sectional area.

\section{Diet and sutural gaps}

S. purpuratus was collected subtidally near Bodega Bay and kept for one year in flow-through seawater aquaria at Bodega Marine Laboratory. Urchins were assigned randomly to one of two diet treatments. The fed group received seaweed ad libitum (180 kg over 1 year, or an average of
$5 \mathrm{~g}$ per urchin per day), unfiltered seawater, and normal room light. The starved group was given no seaweed, filtered incoming water, and reduced light, which reduced algal growth on the aquarium walls. At the start of the experiment, all urchins were marked with a tetracycline label as in Ebert (1982). After one year the urchins were sacrificed and bleached and the tetracycline label was inspected. Skeletal diameter $( \pm 0.5 \mathrm{~mm})$ and weight $( \pm 0.1 \mathrm{~g})$ were measured, and the sutures were visually inspected.

To quantify sutural looseness, vibrational properties of the skeletons were measured as follows. A 3.5-g weight was hung on the end of a string attached to a crossbeam hanging above a rubber-lined box of dimensions 28 by 18 by $12 \mathrm{~cm}$. An urchin skeleton's vibrational properties were tested by placing the skeleton in the box and positioning the cross-beam so that the weight hung vertically down to a point just $2 \mathrm{~mm}$ from the ambitus. The weight was then lifted to a $30^{\circ}$ angle to the vertical and released. The weight swung and hit the skeleton, causing a sound that was recorded with a microphone and analyzed with spectral and cross-correlation procedures. The pattern of frequencies at which a particular urchin vibrated was analyzed statistically with respect to diet, urchin diameter, and skeletal strength under apical loading.

\section{Results}

\section{Crushing of whole skeletons}

Removal of the peristomial membrane had no effect on diameter-specific breaking forces of skeletons with intact sutural ligaments (Fig. 2). A simultaneous regres-

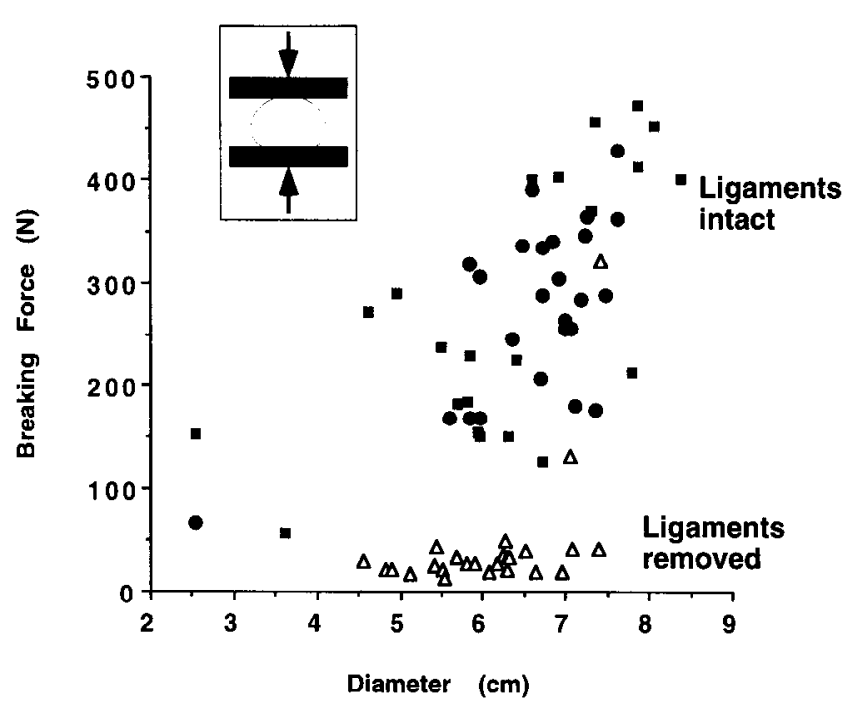

Figure 2. Breaking force of Strongylocentrotus purpuratus skeletons as a function of diameter. Bleached skeletons (open triangles) broke at much lower forces than did fresh skeletons with ligaments intact (solid circles). Removing the peristomial membrane from fresh intact skeletons (solid squares) did not decrease the strength of the skeleton relative to intact skeletons. 


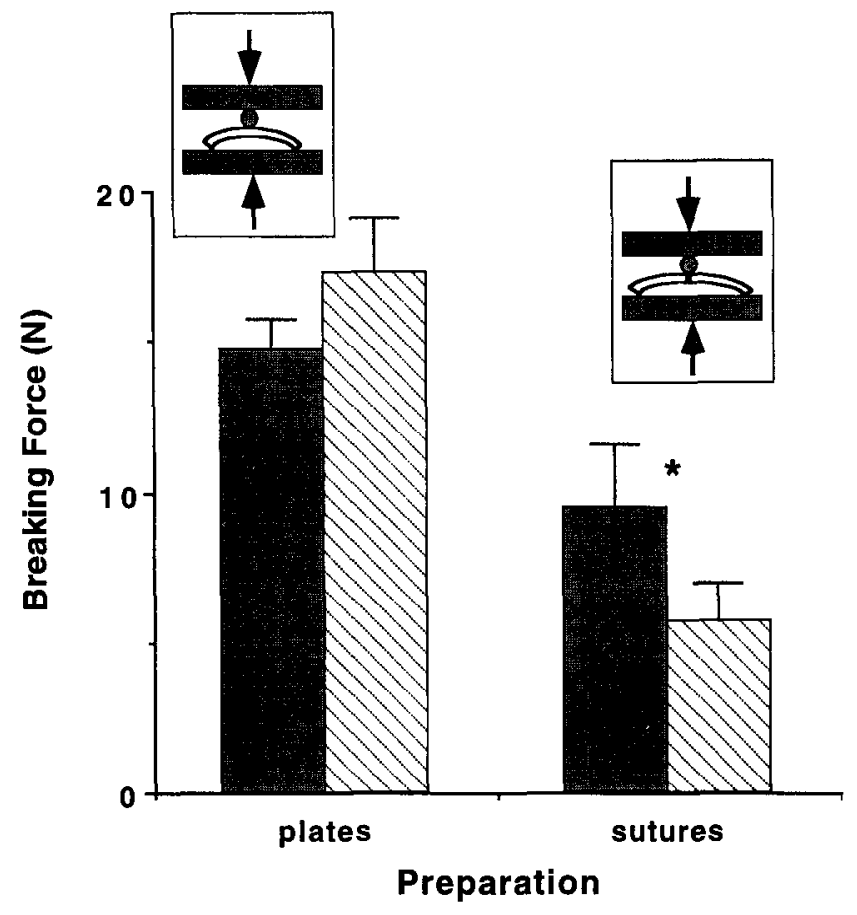

Figure 3. In threc-point bending, bleached (hatched) meridional sutures broke at significantly lower forces than did fresh (solid) meridional sutures, whereas bleaching did not affect the breaking force of plates. Asterisk indicates significant difference. Error bars indicate one standard error.

sion with two slopes and two intercepts did not explain significantly more variation than did a single slope with a single intercept $(P=0.5, F$ test, d.f. $=1,44$ : regression with dummy variables; Weisberg, 1980). For all skeletons with intact ligaments: breaking force $=-79+55$ diameter, where diameter is in centimeters and force is in newtons; the intercept was not significantly different from zero, but the slope was significantly different from zero $\left(P<0.001, F\right.$ test, d.f. $\left.=1,45, r^{2}=0.42\right)$.

In contrast, with the exception of two high outliers, bleached skeletons had much lower breaking strength than skeletons with intact ligaments (Fig. 2). When data from all urchins with intact ligaments were pooled and the two outliers were excluded, simultaneous regression of force on diameter showed that a model with two slopes and two intercepts for the intact versus removed ligaments explained significantly more variation than did a model with one slope and two intercepts $(P<0.05, F$ test, d.f. $=1,66$ : regression with dummy variables; Weisberg, 1980). Further, among bleached urchins, there was no significant variation of breaking force with diameter; neither intercept nor slope were significantly different from zero $(P=0.1, F$ test, d.f. $=1,21)$.

\section{Three-point breakage of plates and meridional sutures}

The urchins ranged in diameter from 4.1 to $7.3 \mathrm{~cm}$, with only one being more than $5.3 \mathrm{~cm}$. Over this limited size range, breaking force of test pieces was independent of urchin diameter, height, or nominal cross-sectional area (plate or suture thickness multiplied by plate or suture width) (linear regressions, probabilities of slope equal to zero ranging between 0.17 and 0.90 ). Fresh sutures broke at a higher mean force than did bleached sutures $(P<$ 0.05 , Mann-Whitney $U$ test, 13 pairs of sutures), whereas fresh and bleached plates broke at similar forces $(P=$ 0.5 , Mann-Whitney $U$ test, 14 pairs of plates) (Fig. 3). (We used the nonparametric $U$ test instead of a paired $t$ test to compare bleached and fresh specimens because the differences between the breakage forces of the paired sutures were not normally distributed: Shapiro-Wilk $W$ test, $P<0.003$ ).

\section{Tensile tests of circumferential sutures}

The nominal breaking stress of circumferential sutures (Fig. 4) was significantly different (2-way ANOVA) by position of the suture on the skeleton $(P<0.0001$, d.f. $=2,95)$ and in bleached versus fresh sutures $(P<0.0001$, $\mathrm{df}=1,95)$; furthermore, there was an interaction between position and bleaching $(P<0.0001$, d.f. $=2,95)$. Grouping all positions, the 54 bleached sutures had a lower nominal breaking stress than the 47 fresh sutures $(P \leq$ 0.0001 , Mann-Whitney $U$ test). Also, at each position bleached sutures had a lower nominal breaking stress than fresh sutures (all $P<0.05$, Mann-Whitney $U$ tests).

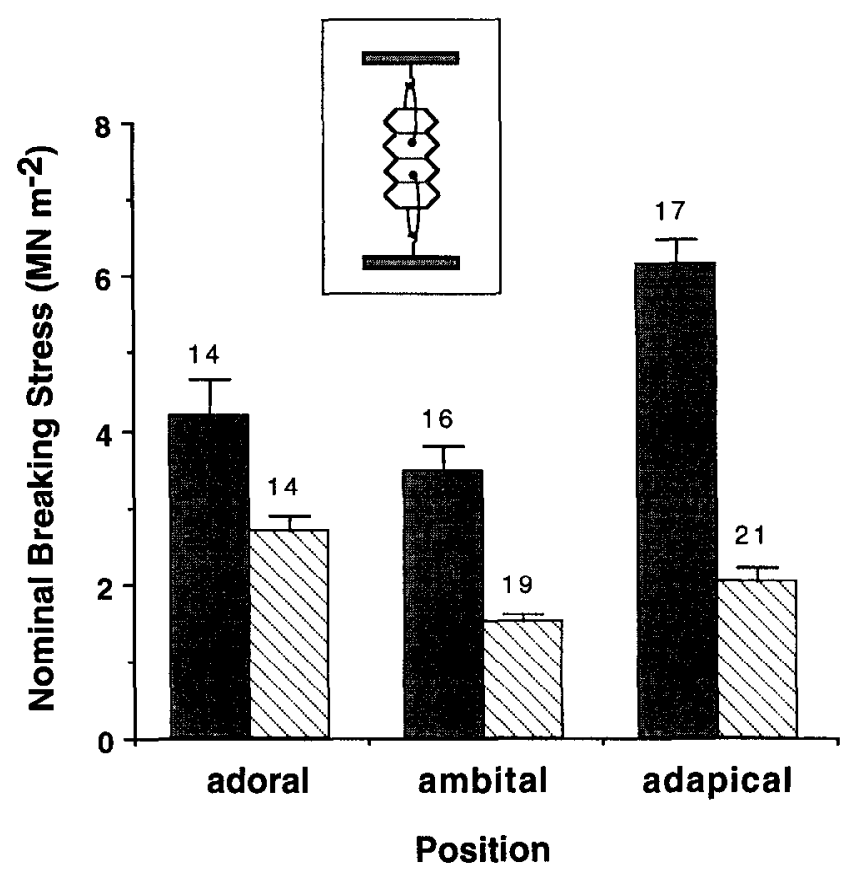

Figure 4. At each position, nominal breaking stress was significantly greater for fresh (solid) than for bleached (hatched) circumferential sutures. Error bars indicate one standard error. Numbers shown are sample sizes. 
Among bleached sutures, position had a significant effect $(P \leq 0.0001,1$-way ANOVA, d.f. $=2,53)$, with all positions differing significantly from all other positions (all $P<0.05$, Fisher PLSD). Among fresh sutures, position also had a significant effect $(P \leq 0.0001,1$-way ANOVA, d.f. $=2,26)$, with adapical sutures being significantly stronger than ambital or adoral sutures $(P<0.05$, Fisher PLSD).

\section{Diet and sutural gaps}

At the edges of plates, the skeletons of all fed urchins showed tetracycline marks (visualized under ultraviolet light) plus a band of new unmarked calcite added at the edge of plates. In contrast, in the skeletons of unfed ur- chins the tetracycline mark could not be found or was only dimly detectable at the very edge of plates. In the unfed urchins in which a trace of tetracycline mark was detectable, no new calcite was visible around the tetracycline marks at the plate edges. Thus, fed urchins had grown, whereas unfed urchins had shrunk or maintained size during the year.

Fed urchins had wider sutural gaps than did unfed urchins (Fig. 5). In 23 of 99 fed urchins, the sutural gaps were large enough to be visible to the naked eye, and 14 of those 23 urchins fell apart (disarticulated) under their own skeletal weight when bleached. Sutural gaps were most prominent in adapical regions. For example, in the 9 urchins with visible gaps, but in which the skeletons did not disarticulate, the visibly gaping sutures always
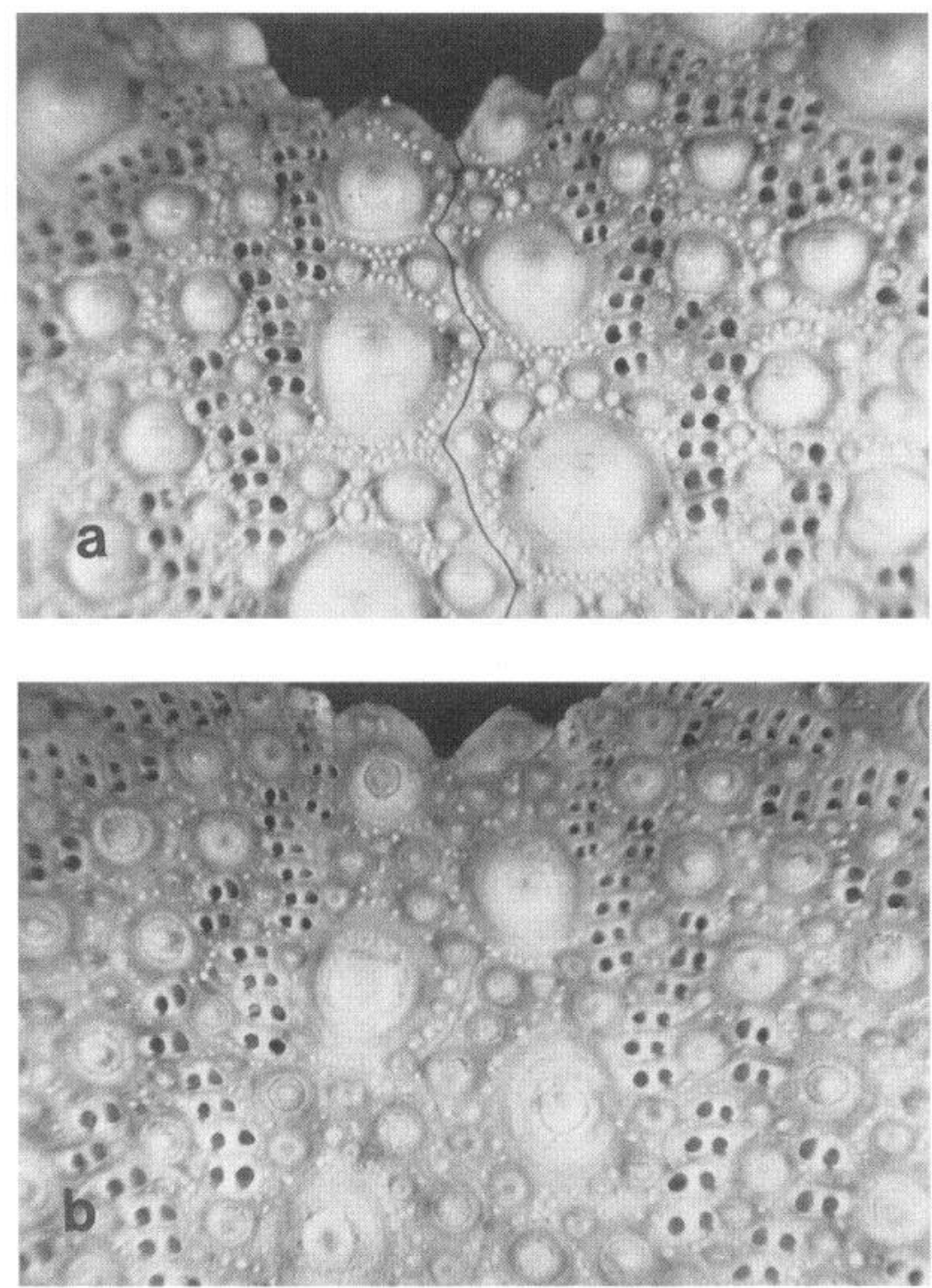

Figure 5. A gap is visible in the apical sutures of skeletons of many well-fed (A) but of no unfed (B) urchins. Typically, well-fed urchins have looser sutures than do unfed urchins. 
occurred above the ambitus; the most adapical plate rows tended to fall out of the skeleton, and vertically gaping sutures tended to be more widely gaped adapically. In contrast, the skeletons of the 100 unfed urchins did not fall apart when bleached and no sutural gaps were visible.

The looseness of the sutures of fed urchins was reflected in a smaller weight for a given diameter in comparison to unfed urchins (Fig. 6). A simultaneous regression of $\log$ [weight] on $\log$ [diameter] with two slopes and two intercepts does not explain significantly more variation than does a model with a single slope and two intercepts $(P=0.7, F$ test, d.f. $=1,195$ : regression with dummy variables: Weisberg, 1980). A model with one slope and two intercepts, however, does explain significantly more variation than a model with just a single slope and a single intercept $\left(P<0.001, F\right.$ test, d.f. $=1,196, r^{2}=0.9$ : regression with dummy variables; Weisberg, 1980). Thus, the bleached skeletons of fed urchins had a significantly lower weight for a given diameter.

Another indication of sutural looseness in urchins is given by the frequency composition of the sound created when a bleached urchin skeleton vibrates after being struck by a weight (Fig. 7). Bleached skeletons of unfed urchins vibrated, or rang, at a series of discrete frequencies, which made a pingy sound like a bell. In contrast, bleached skeletons of fed urchins vibrated for a shorter time at a broad range of frequencies without identifiable discrete frequency components, which makes a dull sound.

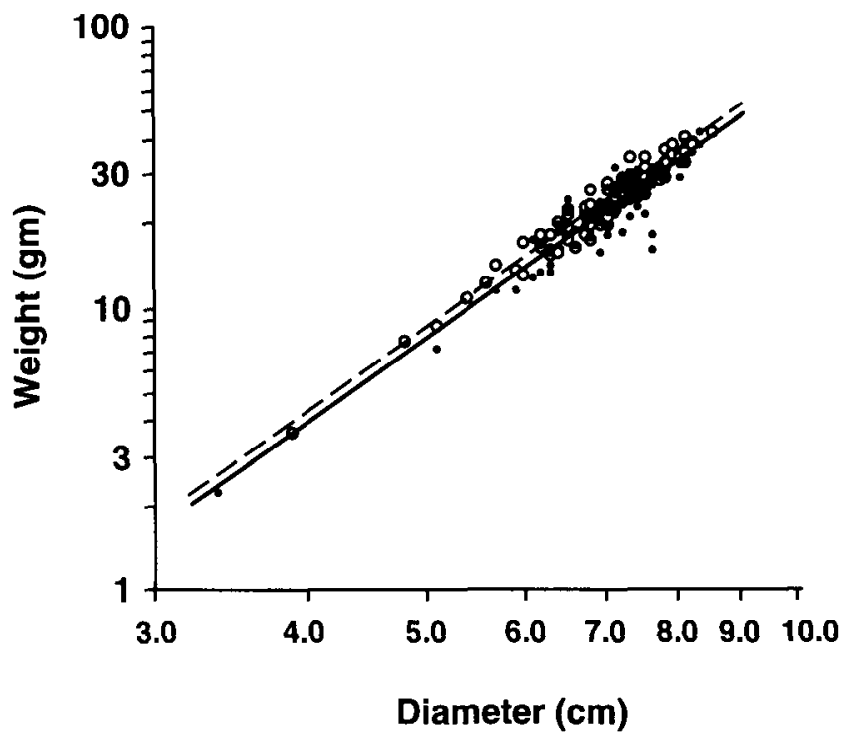

Figure 6. Fed urchins (solid points and line) have significantly lighter skeletons for a given diameter than do unfed urchins (open circles and dashed line). This difference is interpreted as reflecting the larger sutural gaps and general looseness of the plates of fed urchins in comparison to unfed urchins. Regression lines shown have equal slopes but different intercepts.

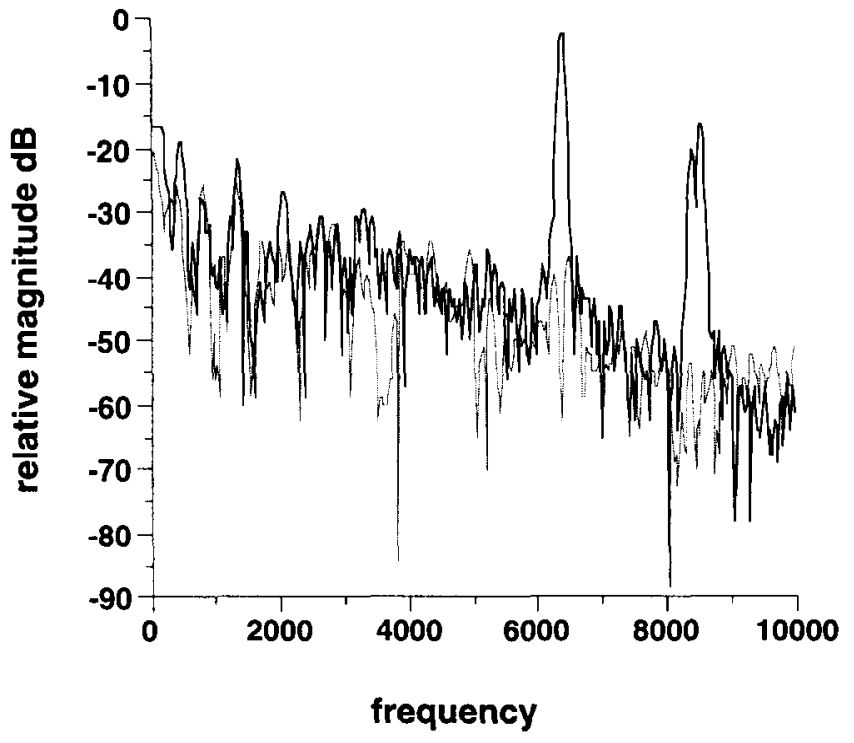

Figure 7. Characteristic frequency spectra of sounds emitted by vibrating, bleached urchin skeletons. Fed urchins ring or ping like a bell when struck; a skeleton-specific set of discrete frequencies of vibration are detectable (solid line). In contrast, unfed urchins emit a dull "thud"; no discrete frequencies are identifiable (dotted line).

For bleached skeletons of unfed urchins, the frequency spectrum is similar to that typical of three-dimensional vibrating objects such as drums or rectangular blocks (Kinsler et al., 1982). The lowest of the identifiable frequency peaks is correlated with urchin diameter $(P \leq$ 0.0001 , correlation $=-0.81, r^{2}=0.66, n=100$, frequency $=-940$ diameter $+1.1 \times 10^{4}$, with diameter in centimeters and frequency in hertz). The negative correlation between frequency and diameter indicates that the size of the urchin skeleton determines some of the modes of vibration, and thus that vibrations are transmitted across sutures and throughout the skeleton. In contrast, bleached skeletons of fed urchins had no identifiable frequency peaks, thus indicating that vibrational energy was lost at loose sutures and that the structure as a whole did not vibrate.

Skeletal vibrations can be used as a measure of sutural loosencss. The cross-correlation between the sound produced by a bleached skeleton and the predicted ringing frequency is a measure of looseness. The predicted ringing frequency is calculated using the empirical linear relationship between frequency and diameter given above. Bleached skeletons of 9 fed urchins that produced the qualitatively dullest sounds had lower cross-correlations $(P<0.001, U$ test $)$ and lower breaking forces $(P<0.001$, $U$ test) than did 25 randomly chosen skeletons of fed urchins (Fig. 8). The 25 randomly chosen fed urchin skeletons had lower cross-correlations $(P<0.01, U$ tests $)$ and lower breaking forces $(P<0.01, U$ tests) than did 25 randomly chosen unfed skeletons. Within the randomly 


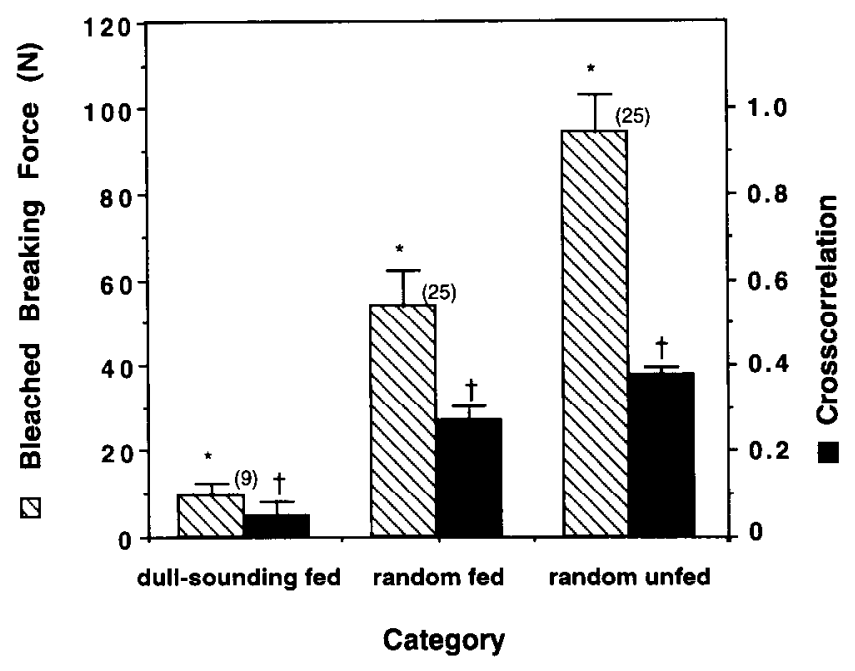

Figure 8. The qualitatively dullest sounding of the fed urchin skeletons had lower mean breaking force and cross-correlation than did randomly chosen fed urchin skeletons. Randomly chosen unfed urchin skeletons have significantly higher mean breaking force and cross-correlation than do randomly chosen fed urchin skeletons. The relationship between breaking force and cross-correlation indicate that loose sutures weaken bleached skeletons. Crosses indicate significant differences in cross-correlation, asterisks indicate significant differences in bleached breaking force.

chosen fed skeletons, brcaking force was significantly correlated with the cross-correlation $(P \leq 0.01, r=0.51$, $r^{2}=0.26, n=25$ ); in contrast, there was no significant correlation between breaking force and cross-correlation for randomly chosen unfed urchin skeletons.

\section{Discussion}

Sutural ligaments strengthen urchin skeletons under a variety of loadings. Under apical loading, whole skeletons broke at higher, size-specific forces when ligaments were intact than when they were removed by bleaching (Fig. 2). In three-point bending, meridional interambulacral sutures with ligaments broke at higher forces than did paired sutures without ligaments (Fig. 3). And in circumferential interambulacral sutures with ligaments, sutures broke at higher nominal stresses than did sutures without ligaments (Fig. 4). The consistency of skeletal strengthening by ligaments, despite differences in imposed stresses, suggests that sutural ligaments reinforce urchin skeletons under natural loads as varied as crushing forces from crab claws, apical or lateral forces from waves, and forces generated when an urchin wedges itself in a crack.

The importance of sutural ligaments in strengthening an urchin's skeleton depended on urchin size. Smaller Strongylocentrotus purpuratus were strengthened less by ligaments than were larger ones (Fig. 2). Size-specific strengthening may be important across taxa as well; the echinoid Echinocyamus pusillus, which is the only species reported to lack ligaments, is a very small echinoid (Telford, 1985b) growing to a typical maximum size of only about $1 \mathrm{~cm}$ in diameter. Sutural ligaments were present in all eight other regular and irregular echinoid genera surveyed (Moss and Meehan, 1967; Telford, 1985a), and are present (pers. obs.) in four Strongylocentrotidae ( $S$. purpuratus, S. droebachiensis, S. franciscanus, and Allocentrotus fragillis), all of which grow to larger sizes.

The degree of structural strengthening by sutural ligaments depends on the position of a suture. The faster growing ambital and adapical sutures (Deutler, 1926) were strengthened more than slower growing adoral sutures (Fig. 4). The faster growing adapical sutures also had the largest sutural gaps (Fig. 5), and larger gaps are associated with more and longer ligaments (Telford, 1985a). Such differences in composition and properties of different skeletal regions can influence deformation, stress distribution, and breakage. For instance, interambulacral areas were slightly stiffer than ambulacral areas in Echinus esculentus, and that difference influenced deformations and bending stresses calculated using finite element analysis (Philippi and Nachtigall, 1996). The lower stiffness of ambulacra compared to interambulacra of $E$. esculentus might be attributable to the difference in the relative proportion of sutures and plates because ambulacral areas have a higher proportion of sutures. The material properties of different portions of the skeleton may generally depend on the relative area covered by sutures, especially gaping sutures with relatively more and longer ligaments.

Not only do the faster growing sutures (adapical and ambital) gape more than the slower growing (adoral) sutures on an individual urchin, but sutures on faster growing urchins are looser than corresponding sutures on nongrowing urchins (Figs. 5-8). Similarly, in S. franciscanus, fed urchins develop looser sutures than starved urchins (pers. obs.).

The relationship between sutural looseness and growth has potential implications for interpretation of the taphonomy of fossil urchins and other echinoderms. Disarticulated skeletons have often been used to imply the species composition, biodiversity, and relative abundance of fossil assemblages of echinoderm species (e.g.: Gordon and Donovan, 1992; Nebelsick, 1996). In an attempt to identify taphonomic biases in such studies, the species-specific tendency to disarticulate has been estimated (Greenstein, 1991) and possible biases interpreted (Greenstein, 1992). Disarticulation times dependent on temperature have also been demonstrated and their taphonomic consequences explored (Kidwell and Baumiller, 1990). Our study adds another variable to these temperature- and species-specific effects. Specifically, the tendency to disarticulate depends on the growth status of a given urchin at the time of fossilization. Since looseness 
is growth-rate dependent, taphonomic biases likely exist between faster and slower growing age classes as well as between faster and slower growing taxa.

In some urchins, differences in sutural gaping due to diet have been attributed to shrinkage of the starved urchins (Ebert, 1967; Levitan, 1988; Constable, 1993), but in $S$. droebachiensis we have observed that sutural gaping was due mainly to expansion of sutures in the fed group (Johnson, A. S., Bowdoin College, et al., unpubl. data). In that study, we additionally observed that as fed urchins grew, the viscoelastic material properties of the sutures changed. Those changes were probably due to changes both in the degree of interlocking of trabeculae and in the material properties of the sutural ligaments. Similarly, material property changes in ligaments have been observed in the continuously growing teeth of sand dollars (Ellers and Telford, 1996) and sea urchins (Birenheide and Motokawa, 1996; Birenheide, et al., 1996), in which the teeth are held in place on the jaw by dental ligaments. These dental ligaments soften periodically and enable a tiny muscle to advance the teeth (Ellers and Telford, 1997; Telford and Ellers, 1997). Thus, material property changes and rearrangements of ligaments occur during growth of echinoids.

Such viscoelastic properties of ligaments may be important in modeling the mechanical behavior of an urchin skeleton. They are important for three reasons. Firstly, as we demonstrated in the current study, the ligaments have a predominant role in providing structural strength, at least during times of growth. Secondly, as we demonstrated here, the gaping of the sutures varies during growth, and therefore the relative contribution of the calcite trabeculae and the ligaments to structural strength also varies during growth. Thirdly, the material properties of the ligaments may change during growth, or possibly over behavioral time spans. Therefore, time-dependent material behaviors such as creep and stress-relaxation must be considered in modeling the mechanics of urchin skeletons. Previous mechanical finite-element models have only considered more conventional measures such as stiffness (Baron, 1991b; Philippi and Nachtigall, 1996). Time-dependent properties of sutural ligaments could change very rapidly if they were mutable collagenous tissue (MCT) (Wilkie, 1996). MCT is a special tissue, known only in echinoderms, that is innervated and that can change material properties over behavioral time spans. Alternatively, sutural ligaments may change material properties over developmental time spans by reorganizing connective tissue constituents as is common in vertebrate connective tissues, e.g., the cervix in late pregnancy (Winn et al., 1993).

The flexibility of sutural joints resulting from sutural gaping and the predominant role of ligaments in growing urchins also has consequences for determining the shape of urchin skeletons. The shape of a sea urchin's skeleton is closely approximated by a mathematical mechanical model that is more conventionally used to describe the shape of water droplets (Ellers, 1993). This model assumes that the droplet's surface, or urchin's skeleton, has zero flexural stiffness. That assumption seems initially unreasonable given that calcite plates are flexurally stiff, but the looseness of sutures during growth provides the flexibility assumed by the model. An urchin's skeleton, with its combination of flexurally stiff plates and more flexible sutures, thus behaves as a flexible jointed membrane during times of growth.

The calculation of urchin shapes (Ellers, 1993) also assumes that an urchin's skeleton behaves like a thin membrane in which bending stresses are negligible. A shell is conventionally considered "thin" if the ratio of the radius of curvature to the thickness is greater than 20 . In $E$. esculentus that ratio is less than 20, and accordingly a finite-element model was used to calculate bending stresses in the skeleton of that species (Philippi and Nachtigall, 1996). Many urchins, however, have much thinner shells and correspondingly higher ratios, in which a thin membrane model is appropriate. Some urchins, such as Allocentrotus fragillis, have extremely thin shells. Others, such as the diadematoid urchins Astropyga pulvinata and Chaetodiadema pallidium, are sufficiently thin-walled and loose-sutured that their skeletons deform by bending when touched lightly. Finally, the "soft-tested" echinothurioid urchins have numerous small, thin imbricate plates imbedded in a meshwork of collagenous ligaments and can deform and contort their skeleton flexibly. ('They can even adjust their shape to fit in right angles and corners of an aquarium, pers. obs.) They have internal sheets of radial muscles (Tsuchiya and Amemiya, 1977) that control the bending of their flexible, thin-walled, nembranous skeleton.

Thus, urchin skeletons can be viewed statically as a continuum of flexibility and thickness, from relatively rigid and thick-walled (e.g., Echinus) to quite flexible and thin-walled (e.g., echinothurioids). All urchin skeletons can be better understood dynamically as flexible, jointed membranes with varying degrees of flexibility and sutural lonseness depending on growth stage.

\section{Acknowledgments}

Thanks to two anonymous reviewers who provided helpful suggestions; S. Keen, H. Leddy, and E. Pearson who critically read the manuscript; and S. Franklin and B. Lindsay who assisted with the experiments. This research was supported by grants from the University of California: Agricultural Research Station Grant \#5134-H and a Bodega Marine Lab Travel Grant both to O. Ellers; as well as a President's Undergraduate Fellowship and a Howard Hughes SHARP Fellowship, both to P. Moberg. 


\section{Literature Cited}

Baron, C. 1991a. What functional morphology cannot explain, a model of sea urchin growth and a discussion of the role of morphogenetic explanations in evolutionary biology. Pp. 471-488 in The Unity of Evolutionary Biology, Vols. 1 \& 2; Fourth International Congress of Systematic and Evolutionary Biology, College Park, Maryland, 1990, E. C. Dudley, ed. Dioscorides Press, Portland, Oregon.

Baron, C. J. 1991b. The structural mechanics and morphogenesis of extant regular echinoids having rigid tests. Ph.D. thesis, University of California at Berkeley.

Birenheide, R., and T. Motokawa. 1996. To be stiff or to be softthe dilemma of the echinoid tooth ligament. I. Morphology. Biol. Bull. 190: $218-230$.

Birenheide, R., A. Tsuchi, and T. Motokawa. 1996. To be stiff or to be soft - the dilemma of the echinoid tooth ligament. II. Mechanical properties. Biol. Bull. 190: 231-236.

Constable, A. J. 1993. The role of sutures in shrinking of the test in Heliocidaris erythrogramma (Echinoidea: Echinometridae). Mar. Biol. 117: 423-430.

Dafni, J. 1986. A biomechanical model for the morphogenesis of regular echinoid tests. Paleobiology 12: 143-160.

Dafni, J. 1988. A biomechanical approach to the ontongeny and phylogeny of echinoids. Pp. 175-188 in Echinoderm Phylogeny and Evolutionary Biology, C. R. C. Paul and A. B. Smith, eds. Clarendon Press, Oxford.

Deutler, F. 1926. Über die Wachstum des Seeigelskeletts. Zool. $J b$. Abt. Anat. Ontog. Tier. 48: 119-200.

Ebert, T. A. 1967. Negative growth and longevity in the purple seaurchin Strongylocentrotus purpuratus (Stimpson). Stience 157: $557-558$.

Ebert, T. A. 1982. Longevity, life history, and relative body wall size in sea urchins. Ecol. Monogr. 52: 353-394.

Ellers, 0. 1993. A mechanical model of growth in sea urchins: predictions of shape and a developmental morphospace. Proc. R. Soc. Lond. B 254: 123-129.

Ellers, O., and M. Telford. 1996. Advancement mechanics of growing teeth in sand dollars (Echinodermata, Echinoidea): a role for mutable collagenous tissue. Proc. R. Soc. Lond. B 263: 39-44.

Ellers, O., and M. Telford. 1997. Muscles advance the teeth in sand dollars and other sca urchins. Proc. R. Soc. Lond. B 264: 15251530.

Gage, J. D. 1991. Skeletal growth zones as age-markers in the sea urchin Psammechinus miliaris. Mar. Biol. 110: 217-228.

Gage, J. D. 1992a. Growth bands in the sea urchin Echinus esculentus: results from tetracycline-mark recapture. J. Mar. Biol. Assoc. UK 72: $257-260$.

Gage, J. D. 1992b. Natural growth bands and growth variability in the sea urchin Echinus esculentus - results from tetracycline tagging. Mar. Biol. 114: 607-616.

Gordon, C. M., and S. K. Donovan. 1992. Disarticulated cchinoid ossicles in paleoecology and taphonomy; the last interglacial Falmouth formation of Jamaica. Palaios 7: 157-166.

Greenstein, B. J. 1991. An integrated study of echinoid taphonomy: predictions for the fossil record of four echinoid families. Palains 6: $519-540$.

Greenstein, B. J. 1992. Taphonomic bias and the evolutionary history of family Cidaridae (Echinodermata; Echinoidea). Paleobiology 18: $50-79$.

Kidwell, S. M., and T. Baumiller. 1990. Experimental disintegration of regular echinoids: roles of temperature, oxygen, and decay thresholds. Paleobiology 16: 247-271

Kinsler, L. E., A. R. Frey, A. B. Coppens, and J. V. Sanders. 1982. Fundamentals of Acoustics, 3rd Ed. John Wiley, New York.

Levitan, D. R. 1988. Density-dependent size regulation and negative growth in the sea urchin Diadema antillarum Philippi. Qecologia 76: $627-629$.

Moss, M. L., and M. M. Meehan. 1967. Sutural connective tissues in the test of an echinoid Arbacia punctulata. A6: 279 304.

Nebelsick, J. H. 1996. Biodiversity of shallow-water red sea echinoids: implications for the fossil record. J. Mar. Biol. Ass. UK 76: 185-194.

Pearse, J. S., and V. B. Pearse. 1975. Growth zones in echinoid skeleton. Am. Zool. 15: 731-753.

Philippi, U., and W. Nachtigall. 1996. Functional morphology of regular echinoid tests (Echinodermata, Echinoida): a finite element study. Zoomorphology 116: 35-50.

Telford, M. 1985a. Domes, arches and urchins: the skeletal architecture of echinoids (Echinodermata). Zoomorphology 1105: 114-124.

Telford, M. 1985b. Structural analysis of the test of Echinocyamus pusillus (O. F. Muller). Pp. 353-360 in Fifth International Echinoderm Conference, Galway, Ireland, 1984, B. F. Keegan and B. D. S. O'Connor, eds. Balkema, Rotterdam.

Telford, M., and O. Ellers. 1997. Tooth advancement muscles in the sand dollar, Echinarachnius parma. Invert. Biol. 116: 255-261.

Tsuchiya, T., and S. Amemiya. 1977. Studies on the radial muscle of an echinothuriid sea-urchin, Asthenosoma-I. Mechanical responses to electrical stimulation and drugs. Comp. Biochem. Physiol. 57: $69-73$.

Weisberg, S. 1980. Applied Linear Regression, John Wiley, New York.

Wilkie, I. C. 1996. Mutable collagenous tissues: extracellular matrix as mechano-effector. Pp. 61-102 in Echinoderm Studies 5, M. Jangoux and J. M. Lawrence, eds. Balkema, Rotterdam.

Wilkie, I. C., M. D. C. Carnevali, and F. Andrietti. 1993. Variable tensility of the peristomial membrane of the sea-urchin Paracentrotus lividus (Lamarck). Comp. Biochem. Physiol. 105A: 493-501.

Winn, R. J., M. B. O'day-Bowman, and O. D. Sherwood. 1993. Hormonal control of the cervix in pregnant gilts IV. Relaxin promotes changes in the histological characteristics of the cervix that are associated with cervical softening during late pregnancy in gilts. Endocrinology 133: 121-128. 